УДК 681.3 .06

\title{
О РАСПРОСТРАНЕНИИ КОНСТРУКЦИИ НИБЕРГ НА ПОЛЯ ГАЛУА НЕЧЕТНОЙ ХАРАКТЕРИСТИКИ
}

\author{
о. Н. ЖДАНОВ ${ }^{1}$, А. в. СОкОЛОВ ${ }^{2}$ \\ ${ }^{1}$ Сибирский государственный аэрокосмический университет имени академика М. Ф. Решетнёва, \\ Россия, Красноярск, 660014, пр-т газеты «Красноярский Рабочий», 31 \\ ${ }^{2}$ Одесский национальный политехнический университет, \\ Украина, Одесса, 65044, пр-т Шевченко 1
}

\begin{abstract}
Аннотация. Как известно, $S$-блоки конструкции Ниберг обладают криптографическими свойствами, ценными для практического применения. До настоящего времени эта конструкция рассматривалась только для полей характеристики 2. В данной статье конструкция Ниберг обобщена на поля нечетной характеристики. Введено понятие расстояния нелинейности $p$-функции, построен троичный аффинный код. Построены $S$-блоки подстановки конструкции Ниберг для характеристики поля $p=3$ для всех длин $N \leq 243$. Вычислены их расстояния нелинейности и показано, что они растут с ростом длины $S$-блока подстановки существенно быстрее в сравнении с полями характеристики $p=2$.
\end{abstract}

\section{АКТУАЛЬНОСТЬ ТЕМЫ}

Одним из основных средств обеспечения конфиденциальности информации являются блочные симметричные криптографические алгоритмы. Стремительный рост вычислительной мощности ЭВМ обуславливает необходимость увеличения криптостойкости существующих алгоритмов, а также разработки новых. В этом направлении ведут работу многие исследователи и практики. Устойчивость алгоритма шифрования к наиболее распространенным видам криптоанализа определяется качеством блока замен $-S$-блока подстановки. В настоящее время уже считается общепринятым, что качество узлов замен характеризуется значениями нелинейности и лавинного эффекта $[1,2]$.

\section{ПОДХОДЫ К ФОРМИРОВАНИЮ ТАБЛИЦ ЗАМЕН}

Применительно к формированию таблиц замен можно выделить два основных подхода в разработке алгоритмов шифрования.

Примером первого подхода является признанный очень стойким алгоритм ГОСТ 28147-89 [2], который не определяет метода генерации блоков замен. Алгоритм подразумевает возможность использования различных методик построения блоков замен. Например в [3] предложена обоснованная методика поэтапного выбора булевых функций, являющихся компонентами блока замен, в которой учитываются не только значения нелинейности каждой из функций, составляющих блок, но и нелинейность всех возможных их нетривиальных линейных комбинаций. Отметим также, что при этом возможно одновременно решать задачу повышения устойчивости как к линейному, так и к дифференциальному криптоанализу, если использовать в качестве крите- 


\section{БИБЛИОГРАФИЧЕСКИЙ СПИСОК}

1. Жданов, О. Н. Методика выбора ключевой информачии для алгоритма блочного шифрования. М.: ИНФРА-М, 2013. $90 \mathrm{c.}$

2. Соколов, А.В. Новые методы синтеза нелинейных преобразований современных шифров. Germany: Lap Lambert Academic Pub., 2015. 100 c. 
3. ГОСТ 28147-89. Системы обработки информации. Защита криптографическая. Алгоритм криптографического преобразования. М.: ИПК Издательство стандартов, 1996. 28 с.

4. Mister, S.; Adams, C. Practical S-box design. Proc. of Workshop in Selected Areas of Cryptography, SAC'96, 1996. P. 61-76. URI: http://citeseerx.ist.psu. edu/viewdoc/download?doi=10.1.1.40.7715\&rep=rep1\& type $=$ pdf.

5. Медведева, Т.Е. Оценка криптостойкости таблиц замен алгоритма ГОСТ 28147-89. Решетневские чтения, 2012. C. 666. URI: http://disk.sibsau.ru/website/ reshetnevsite/materials/2012 2.pdf.

6. Чалкин, Т. А. Разработка методики выбора параметров для алгоритма построения узлов замен блочного шифра ГОСТ 28147-89. Актуальные проблемы безопасности информационных технологий: материалы III Международной научно-практической конференции / Под общей ред. О. Н. Жданова, В. В. Золотарева. Красноярск: Сиб. гос. аэрокосмич. ун-т, 2009. С. 33-38.

7. FIPS 197. [Electronic resource] Advanced encryption standard, 2001. URI: http://csrc.nist.gov/publi cations/.

8. Nyberg, K. Differentially uniform mappings for cryptography. Advances in cryptology. Proc. of EUROCRYPT'93, Lecture Notes in Computer Science, Vol. 765, P. 55-65, 1994. DOI: 10.1007/3-540-482 $\underline{85-7 \quad 6 .}$.

9. Мазурков, М.И.; Соколов, А. В. Нелинейные преобразования на основе полных клас сов изоморф- ных и автоморфных представлений поля GF(256). Известия вузов. Радиоэлектроника, Т. 56, № 11, С. 16-24, 2013. URI: http://radio.kpi.ua/article/view/S00213 47013110022.

10. Мазурков, М.И.; Соколов, А. В. Криптографические свойства нелинейного преобразования шифpa Rijndael на базе полных классов неприводимых полиномов. Праиі Одеського політехнічного університету, № 2, C. 183-189, 2012. URI: http://pratsi. opu.ua/articles/show/864.

11. Амбросимов, А.С.Свойства бент-функций q-значной логики над конечными полями. Дискрет. матем., T. 6, № 3, С. 50-60, 1994. URI: http://mi.math net.ru/dm639.

12. Лидл, Р.; Нидеррайтер, Г. Конечные поля. М.: Мир, 1988. 808 с.

13. Kim, Y.-S.; Jang, J.-W.; No, J.-S.; Helleseth, T. On p-ary bent functions defined on finite fields. Mathematical Properties of Sequences and Other Combinatorial Structures. The Springer International Series in Engineering and Computer Science, vol. 726. Springer, Boston, MA, 2002, P. 65-76. DOI: $\underline{10.1007 /}$ 978-1-4615-0304-0 8 .

14. Zhdanov, O. N.; Sokolov, A. V. Block symmetric cryptographic algorithm based on principles of variable block length and many-valued logic. Far East J. Electronics Commun., Vol. 16, No. 3, P. 573-589, 2016. DOI: 10.17654/EC016030573. 